\title{
Room-Temperature Ferromagnetism in Nickel-Doped Wide Band Gap Ferroelectric $\mathrm{Bi}_{0.5} \mathrm{~K}_{0.5} \mathrm{TiO}_{3}$ Nanocrystals
}

\author{
Duong Van Thiet ${ }^{1,2}$, Do Duc Cuong ${ }^{2}$, Luong Huu Bac ${ }^{1}$, Le Viet Cuong ${ }^{3}$, Ha Dang Khoa ${ }^{1}$, \\ Sunglae $\mathrm{Cho}^{2, *}$, Nguyen Hoang Tuan ${ }^{1}$ and Dang Duc Dung,* \\ ${ }^{1}$ School of Engineering Physics, Ha Noi University of Science and Technology, 1 Dai Co Viet Road, Ha Noi, Viet Nam \\ ${ }^{2}$ Department of Physics, University of Ulsan, Ulsan 608-749, Republic of Korea \\ ${ }^{3}$ Laboratory for Micro-Nano Technology, University of Engineering and Technology, \\ VNUH, 144 Xuan Thuy Road, Ha Noi, Viet Nam
}

We report the effect of nickel doping on the structural, optical, and magnetic properties of $\mathrm{Bi}_{0.5} \mathrm{~K}_{0.5} \mathrm{TiO}_{3}$ nanocrystal. The X-ray diffraction results indicated that $\mathrm{Ni}$ was substituted into the $\mathrm{Ti}$ sites in $\mathrm{Bi}_{0} \mathrm{~K}_{05} \mathrm{TiO}_{3}$ and the $\mathrm{NiTiO}_{3}$ phase was formed when Ni concentration was higher than $3 \mathrm{~mol} \%$. The band gap value decreased from $3.31 \mathrm{eV}$ to $2.96 \mathrm{eV}$ when the $\mathrm{Ni}$ concentration changed from 0 to $3 \mathrm{~mol} \%$ and then increased with higher $\mathrm{Ni}$ concentration. Both weak-ferromagnetism and diamagnetism coexisted in un-doped $\mathrm{Bi}_{0.5} \mathrm{~K}_{0.5} \mathrm{TiO}_{3}$ samples. The ferromagnetic signal strongly influenced the paramagnetic signal for $\mathrm{Ni}$-doped $\mathrm{Bi}_{0.5} \mathrm{~K}_{0.5} \mathrm{TiO}_{3}$ samples at room temperature. The room-temperature ferromagnetism in Ni-doped $\mathrm{Bi}_{0.5} \mathrm{~K}_{0.5} \mathrm{TiO}_{3}$ samples could be contributed by intrinsic reason due to presence of $\mathrm{Ni}$ ion in $\mathrm{Bi}_{0.5} \mathrm{~K}_{0.5} \mathrm{TiO}_{3}$ crystal and by extrinsic reason due to segregation of $\mathrm{NiTiO}_{3}$ clusters when $\mathrm{Ni}$ concentration was over $3 \mathrm{~mol} \%$ threshold. This method may provide a useful way to get both single-phase multiferroics and composite multiferroics materials. [doi:10.2320/matertrans.MA201548]

(Received January 30, 2015; Accepted June 30, 2015; Published August 25, 2015)

Keywords: potassium bismuth titanate, nickel-doped potassium bismuth titanate, multiferroics, ferroelectricity, ferromagnetism

\section{Introduction}

One of the promising approaches to create novel materials is to combine different physical properties in one material to achieve rich functionality. The ideal to combine both ferromagnetic and ferroelectric properties in one system started in 1960s by Smolenskii and Venevtsev. ${ }^{1,2)}$ However, there is a scarcity of multiferroic material in nature because the conditions for being simultaneously ferroelectric and ferromagnetic are difficult to achieve due to the usual atomiclevel mechanism. ${ }^{3,4)}$ Therefore, it remains a major challenge to obtain new multiferroic materials at room temperature. There are four ways to obtain and to develop the multiferroic materials: i) enhancing the performances of natural multiferroic materials such as $\mathrm{BiFeO}_{3}$, ) ii) synthesis of new multiferroic materials such as $\mathrm{KBiFe}_{2} \mathrm{O}_{5}$, , iii) combining ferromagnetic materials with ferroelectric materials as composite or multilayer such as $\mathrm{BaTiO}_{3}-\mathrm{CoFe}_{2} \mathrm{O}_{4}$ or $\mathrm{NiFe} /$ $\mathrm{BiFeO}_{3}$, etc. ${ }^{7,8)}$ and iv) introducing the transition metal to ferroelectric material as dopants such as Fe-doped $\mathrm{BaTiO}_{3} .{ }^{9)}$

Recently, the ferromagnetism at room temperature was obtained in transition metal Mn- and Fe-doped $\mathrm{PbTiO}_{3}$ and $\mathrm{PbTiO}_{3}-\mathrm{CoFe}_{2} \mathrm{O}_{4}$ composite, ${ }^{10-12)}$ However, since $\mathrm{Pb}$ in leadbased material pollutes environment and harmful to human, considerable effort has been devoted towards the development of lead-free multiferroic materials. ${ }^{13)}$ Among lead-free ferroelectric materials, the $\mathrm{Bi}_{0.5} \mathrm{~A}_{0.5} \mathrm{TiO}_{3}(\mathrm{~A}=\mathrm{Na}, \mathrm{K})$ are widely studied. ${ }^{14)}$ Recently, the room temperature ferromagnetism was obtained in transition metal ( $\mathrm{Co}, \mathrm{Fe})$-doped $\mathrm{Bi}_{0.5} \mathrm{Na}_{0.5} \mathrm{TiO}_{3}$ ferroelectric materials. ${ }^{15,16)}$ However, the effects of transition metal in transition metal-doped $\mathrm{Bi}_{0.5} \mathrm{~K}_{0.5^{-}}$ $\mathrm{TiO}_{3}$ (BKT) ferroelectric materials has not been deeply investigated.

*Corresponding author, E-mail: slcho@ulsan.ac.kr, dung.dangduc@hust. edu.vn
In this work, the $\mathrm{Ni}$-doped $\mathrm{Bi}_{0.5} \mathrm{~K}_{0.5} \mathrm{TiO}_{3}$ nanocrystalline materials were fabricated by using sol-gel technique. The $\mathrm{Ni}$ strongly influenced the band structure of $\mathrm{Bi}_{0.5} \mathrm{~K}_{0.5} \mathrm{TiO}_{3}$; reduction of band gap. The $\mathrm{Ni}$ had low solid solution in $\mathrm{Bi}_{0.5} \mathrm{~K}_{0.5} \mathrm{TiO}_{3}$ crystal and the $\mathrm{NiTiO}_{3}$ clusters were formed when Ni concentration dopants are over $3 \mathrm{~mol} \%$. The Nidoped $\mathrm{Bi}_{0.5} \mathrm{~K}_{0.5} \mathrm{TiO}_{3}$ samples exhibited ferromagnetism at room temperature. The saturation magnetization was found to be $\sim 0.875 \mathrm{Am}^{2} / \mathrm{kg}$ at $5 \mathrm{~K}$ for $\mathrm{Bi}_{0.5} \mathrm{~K}_{0.5} \mathrm{Ti}_{0.99} \mathrm{Ni}_{0.01} \mathrm{O}_{3}$ sample.

\section{Experimental Procedures}

The Ni-doped $\mathrm{Bi}_{0.5} \mathrm{~K}_{0.5} \mathrm{TiO}_{3}$ samples were synthesized by using the sol-gel technique. The raw materials used consist of bismuth nitrate pentahydrate $\left(\mathrm{Bi}\left(\mathrm{NO}_{3}\right)_{2} .5 \mathrm{H}_{2} \mathrm{O}\right)$, potassium nitrate $\left(\mathrm{KNO}_{3}\right)$, tetraisopropoxytitanium (IV) $\left(\mathrm{C}_{12} \mathrm{H}_{28} \mathrm{O}_{4} \mathrm{Ti}\right)$, and nickel nitrate $\left(\mathrm{Ni}\left(\mathrm{NO}_{3}\right)_{2} \cdot 6 \mathrm{H}_{2} \mathrm{O}\right)$. The acetic acid $\left(\mathrm{CH}_{3} \mathrm{COOH}\right)$ and acetylacetone $\left(\mathrm{CH}_{3} \mathrm{COCH}_{2} \mathrm{COCH}_{3}\right)$ were selected as solvents. The experimental procedure for the $\mathrm{Ni}$ doped $\mathrm{Bi}_{0.5} \mathrm{~K}_{0.5} \mathrm{TiO}_{3}$ was as follows. Firstly, bismuth nitrate pentahydrate and potassium nitrate were dissolved in acetic acid and $\mathrm{CO}_{2}$-free distilled water $\left(10 \mathrm{ml}\right.$ DI- $\mathrm{H}_{2} \mathrm{O}: 1 \mathrm{ml}$ acetic acid). After stirring vigorously for $1 \mathrm{~h}$, a transparent homogeneous sol was formed. Then, the acetylaceton was introduced into a prepared solution after adding the tetraisopropoxytitanium (IV). After stirring vigorously for $2 \mathrm{~h}$, a thin yellow homogeneous sol was formed. Then, the amounts of nickel nitrate were added. The solutions were stirred around one day at room temperature. Then, the sol was heated at $100^{\circ} \mathrm{C}$ to prepare dry gels. The dry gels were ground and calcined at $400^{\circ} \mathrm{C}$ for $2 \mathrm{~h}$ and sintered at $700^{\circ} \mathrm{C}$ for $3 \mathrm{~h}$. The white potassium bismuth titanate and green nickel-doped potassium titanate powders were obtained. The crystalline structures of the samples were characterized by X-ray diffraction (XRD, Brucker D8 Advance) in range $2 \theta$ from 20 to $60^{\circ}$. The optical properties were studied by UV- 

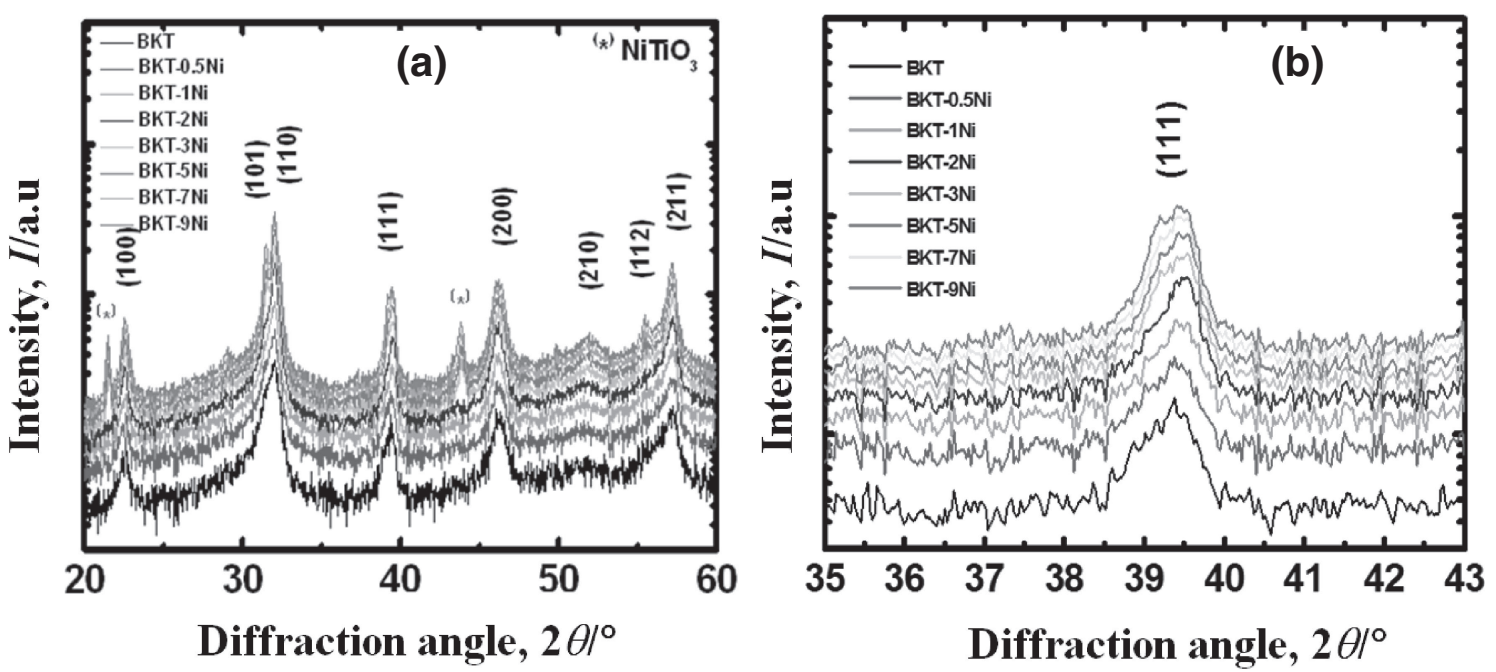

Fig. 1 (a) X-ray diffraction patterns of Ni-doped $\mathrm{Bi}_{0.5} \mathrm{~K}_{0.5} \mathrm{TiO}_{3}$ samples as a function of Ni doping concentration, (b) a comparison of (111) diffraction peak positions.

Vis spectroscopy (Jasco V-670) in wavelength range from 200 to $800 \mathrm{~nm}$. The magnetic properties were characterized by using superconducting quantum interference device (SQUID) magnetometer (Quantum Design, Inc.) at $5 \mathrm{~K}$ and vibration sample magnetometer (Lakeshore 7400) at room temperature.

\section{Results and Discussion}

Figure 1(a) shows the XRD patterns of the Ni-doped $\mathrm{Bi}_{0.5} \mathrm{~K}_{0.5} \mathrm{TiO}_{3}$ samples. The peaks in $\theta-2 \theta$ XRD patterns were indexed as tetragonal phase in perovskite structure. The $\mathrm{NiTiO}_{3}$ phases were found in the logarithmically scaled $\theta-2 \theta$ XRD pattern when $\mathrm{Ni}$ concentration dopant was over $3 \mathrm{~mol} \%$, indicating that $\mathrm{Ni}$ solutes in $\mathrm{Bi}_{0.5} \mathrm{~K}_{0.5} \mathrm{TiO}_{3}$ with low concentration. The (111) peak position in the range of $35-43$ slightly shifted toward a higher $2 \theta$ values with $\mathrm{Ni}$ doping, as shown in Fig. 1(b). The diffraction peak shifted due to transition metal presence at Ti-site and different ionic radii between them. ${ }^{9,10,16,17)}$ Note that the ionic radius of $\mathrm{Ni}$ depends on the coordination number charge and spin states, etc. The ionic radii of $\mathrm{Ni}^{2+}, \mathrm{Ni}^{3+}, \mathrm{Ni}^{4+}$ and $\mathrm{Ti}^{4+}$ with six coordination are $0.069,0.056,0.048$, and $0.061 \mathrm{~nm}$, respectively. ${ }^{18)}$ The extended X-ray absorption fine structure and Xray absorption near-edge structure results indicated that the $\mathrm{Ni}$ charge state is close to $4+$ in Ni-doped $\mathrm{SrTiO}_{3}$, while the $\mathrm{X}$-ray photoelectron spectroscopy result indicated that the $\mathrm{Ni}$ charge state is $2+$ in $\mathrm{Ni}$-doped $\mathrm{BaTiO}_{3}{ }^{19,20)}$ However, Niishiro et al. reported that both $\mathrm{Ni}^{3+}$ and $\mathrm{Ni}^{2+}$ are present in $\mathrm{SrTiO}_{3}{ }^{21)}$ Our result indicate that the peaks position shift to higher angle for doped samples suggests that the average ionic radius of $\mathrm{Ni}$ dopant is smaller than that of ionic $\mathrm{Ti}^{4+}$.

The optical absorption spectra of $\mathrm{Bi}_{0.5} \mathrm{~K}_{0.5} \mathrm{TiO}_{3}$ samples with various $\mathrm{Ni}$ concentrations are shown in Fig. 2(a). Clearly, the Ni doping into $\mathrm{Bi}_{0.5} \mathrm{~K}_{0.5} \mathrm{TiO}_{3}$ below solubility limit makes the spectra red-shift, indicating the reduced band gap $\left(E_{\mathrm{g}}\right)$. In addition, the appearance of absorbance peaks at around 440 and $710 \mathrm{~nm}$ suggest multi-charge-states of $\mathrm{Ni}$. Our results are in accordance with the previous report for Nidoped $\mathrm{SrTiO}_{3}{ }^{22}$ ) The results were further evidence for $\mathrm{Ni}$ cations incorporation into $\mathrm{Bi}_{0.5} \mathrm{~K}_{0.5} \mathrm{TiO}_{3}$. The $E_{\mathrm{g}}$ values were calculated by using the plot of $(\alpha h \nu)^{2}$ versus photon energy $h v$, as shown in Fig. 2(b), where $\alpha$ is absorbance coefficient, $h$ the Planck constant, and $v$ the frequency. Inset of Fig. 2(b) shows the band gap values as function of $\mathrm{Ni}$ doping concentration. The optical band gap is calculated to be $3.31 \mathrm{eV}$ for pure $\mathrm{Bi}_{0.5} \mathrm{~K}_{0.5} \mathrm{TiO}_{3}$ and $2.96 \mathrm{eV}$ for $3 \mathrm{~mol} \% \mathrm{Ni}$ doped $\mathrm{Bi}_{0.5} \mathrm{~K}_{0.5} \mathrm{TiO}_{3}$ and it decreased with further addition of Ni. The reduction of $E_{\mathrm{g}}$ values was recently reported in transition metal-doped ferroelectric perovskite structure. Oanh et al. obtained the reduction of band gap from 2.98 to $1.50 \mathrm{eV}$ in $3 \mathrm{~mol} \% \mathrm{Mn}$-doped $\mathrm{PbTiO}_{3} .{ }^{11)} \mathrm{Hu}$ et al. reported the band gap values of 3.4 and $3.2 \mathrm{eV}$ in pure $\mathrm{PbTiO}_{3}$ film and $2 \mathrm{~mol} \% \mathrm{Fe}$-doped $\mathrm{PbTiO}_{3}$ film, respectively. ${ }^{23)} \mathrm{Xie}$ et al. reported that the absorption tail is partly attributed to the electron excitation from $\mathrm{Fe}$ impurities levels to the conduction band of $\mathrm{SrTiO}_{3}{ }^{24)}$ However, the $E_{\mathrm{g}}$ values increased from 2.96 (3\% mol Ni-doped BKT) to $3.21 \mathrm{eV}(9 \%$ mol Nidoped BKT) with additional $\mathrm{Ni}$ over solubility limit of $\mathrm{Ni}$ in $\mathrm{Bi}_{0.5} \mathrm{~K}_{0.5} \mathrm{TiO}_{3}$. The presentation of low solid solution of $\mathrm{Ni}$ in $\mathrm{Bi}_{0.5} \mathrm{~K}_{0.5} \mathrm{TiO}_{3}$ results in phase separation as $\mathrm{NiTiO}_{3}$.

Figure 3 shows the magnetic hysteresis $(M-H)$ loops of the un-doped and $\mathrm{Ni}$-doped $\mathrm{Bi}_{0.5} \mathrm{~K}_{0.5} \mathrm{TiO}_{3}$ samples at room temperature. The S-shape at low field and anti-S-shape at high field were observed in un-doped $\mathrm{Bi}_{0.5} \mathrm{~K}_{0.5} \mathrm{TiO}_{3}$ samples, indicating the strong diamagnetic contribution, as shown in Fig. 3(a). The clear magnetic hysteresis loop was achieved after subtracting the diamagnetic contribution, as shown in inset of Fig. 3(a). The coercive field $\left(H_{\mathrm{C}}\right)$ and remanence magnetization $\left(M_{\mathrm{r}}\right)$ was estimated about $0.012 \mathrm{~T}$ and $0.2 \mathrm{~m} \mathrm{Am}^{2} / \mathrm{kg}$ for un-doped $\mathrm{Bi}_{0.5} \mathrm{~K}_{0.5} \mathrm{TiO}_{3}$ samples, respectively, which were solid evidence for ferromagnetism at room temperature. The unexpected room temperature ferromagnetism for un-doped $\mathrm{Bi}_{0.5} \mathrm{~K}_{0.5} \mathrm{TiO}_{3}$ samples was attributed to O- and/or Ti-vacancies, ${ }^{11,25-27)}$ or the exchange interactions between localized electron spin moments and oxygen vacancies at the surface of nanoparticels. ${ }^{28)}$ Whereas, the $M-H$ curve becomes S-type shape with the Ni concentration at $3 \mathrm{~mol} \%$, indicating the appearance of ferromagnetic longrange ordering, as shown in Fig. 3(c). The non-zero $H_{\mathrm{C}}$ and 

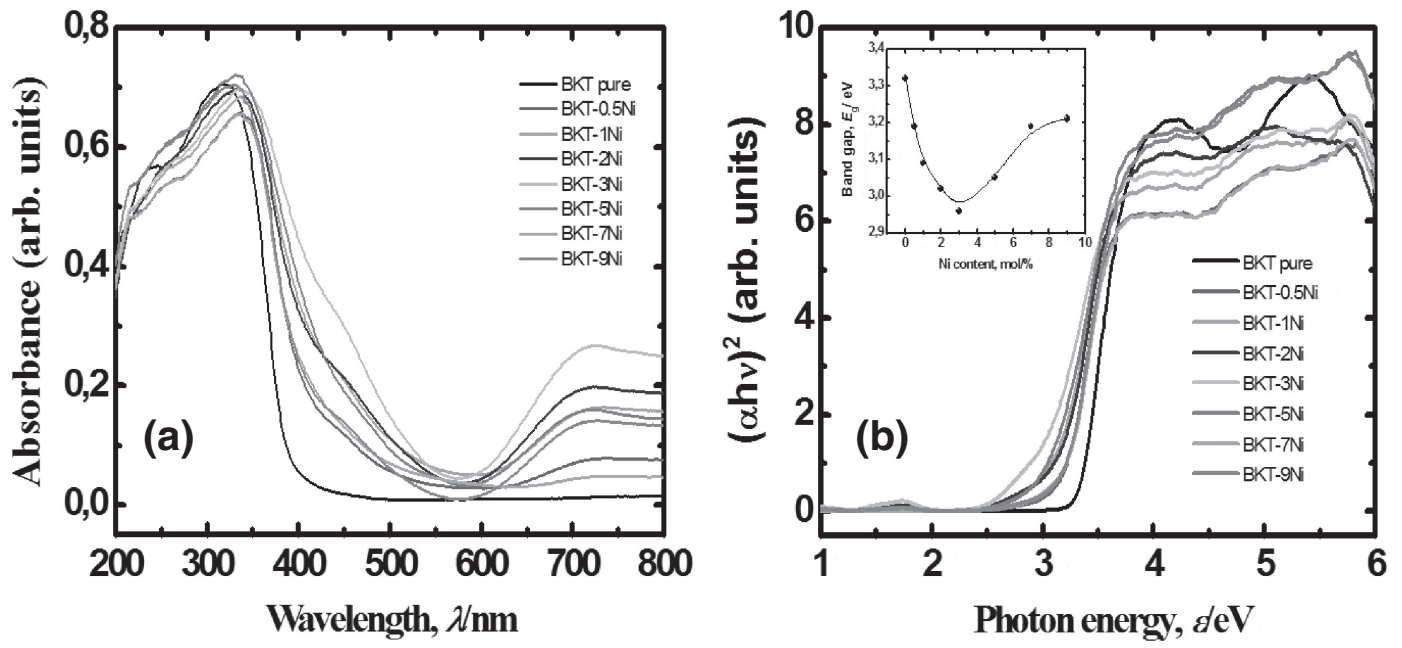

Fig. 2 (a) UV-Vis absorption spectra of the Ni-doped $\mathrm{Bi}_{0.5} \mathrm{~K}_{0.5} \mathrm{TiO}_{3}$ and (b) The $(\alpha h \nu)^{2}$ vs. photon energy $(h \nu)$ of the $\mathrm{Bi}_{0.5} \mathrm{~K}_{0.5} \mathrm{TiO}_{3}$ samples for various $\mathrm{Ni}$ dopants. The inset of (b) shows the band gap $E_{\mathrm{g}}$ of the $\mathrm{Bi}_{0.5} \mathrm{~K}_{0.5} \mathrm{TiO}_{3}$ samples as function of Ni dopant.
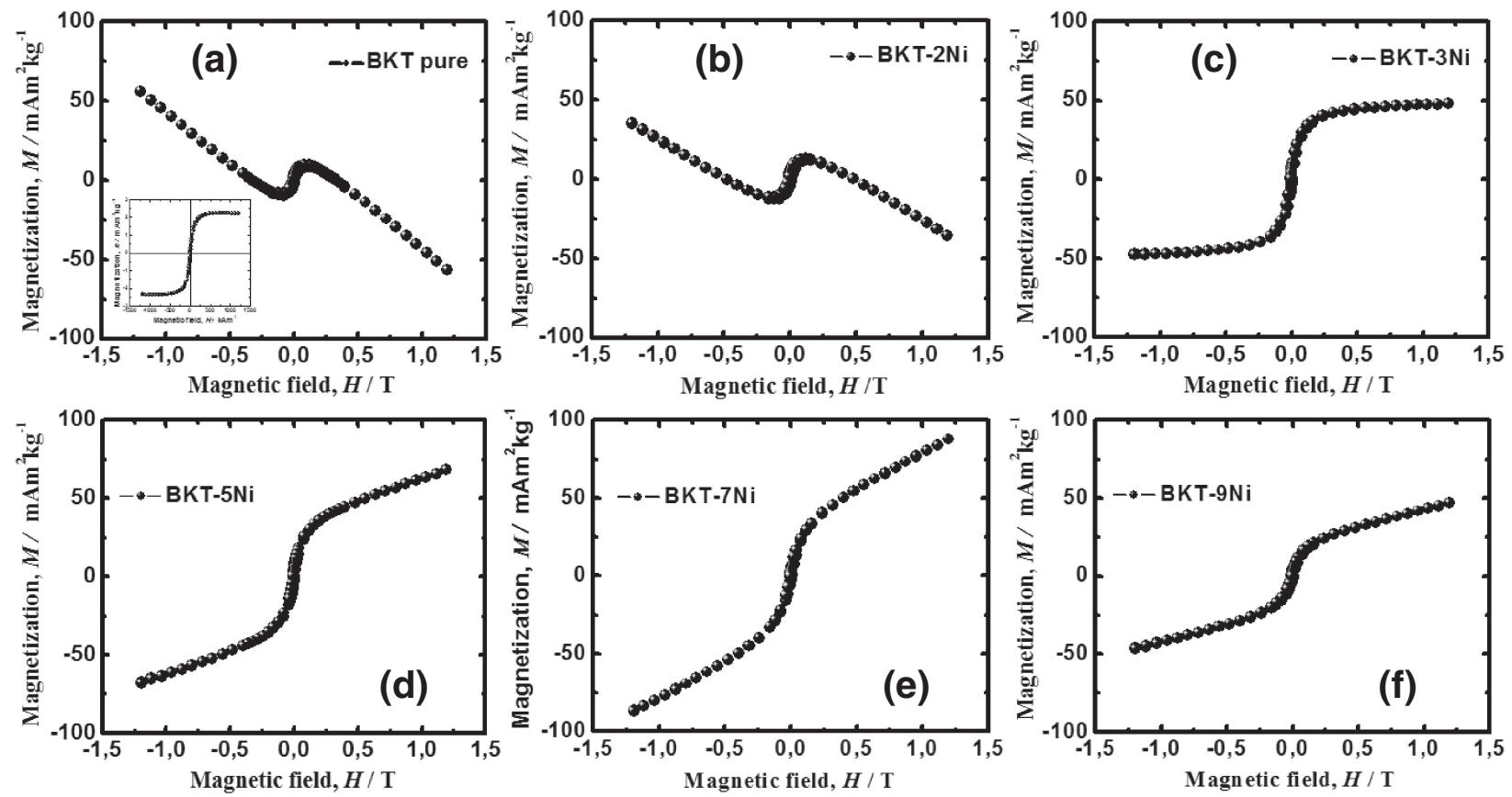

Fig. 3 The as-obtained $M-H$ curve of $\mathrm{Bi}_{0.5} \mathrm{~K}_{0.5} \mathrm{TiO}_{3}$ samples for various Ni do pants at room temperature; (a) un-doped, (b) 2 mol\% Ni-

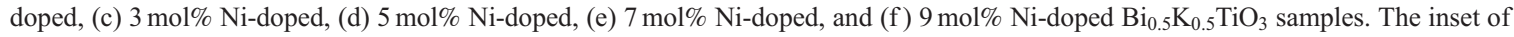
(a) shows the $M-H$ curve of the un-doped $\mathrm{Bi}_{0.5} \mathrm{~K}_{0.5} \mathrm{TiO}_{3}$ samples after subtraction of the diamagnetic signal.

$M_{\mathrm{r}}$ values were obtained; $0.017 \mathrm{~T}$ and $0.41 \mathrm{Am}^{2} / \mathrm{kg}$ of 2 mol\% Ni-doped $\mathrm{Bi}_{0.5} \mathrm{~K}_{0.5} \mathrm{TiO}_{3}$ samples, which were solid evidence for ferromagnetic ordering at room temperature. At higher amount of $\mathrm{Ni}$ dopant, the $M-H$ curve exhibited no saturation. This phenomenon is well known in transition metal-doped wide band gap ferroelectric materials such as Fe-doped $\mathrm{Bi}_{0.5} \mathrm{Na}_{0.5} \mathrm{TiO}_{3}$ or $\mathrm{PbTiO}_{3}$, etc., which results from the contribution of paramagnetic isolated magnetic ion..$^{9,10,15,16)}$ Thus, the observed magnetism in Ni-doped $\mathrm{Bi}_{0.5} \mathrm{~K}_{0.5} \mathrm{TiO}_{3}$ samples is attributed to the competition between ferromagnetism and paramagnetism. For higher Ni-doped $\mathrm{Bi}_{0.5} \mathrm{~K}_{0.5} \mathrm{TiO}_{3}$ samples, e.g. 9 mol\% Ni-doped in this experiment, the volume fraction of $\mathrm{Ni}$ ions increases. It is known that the super-exchange interactions between neighboring $\mathrm{Ni}$ ions are antiferromagnetic. As a result, the enhanced Ni-Ni antiferromagnetic associations suppress the ferromagnetic coupling, resulting in a rapid decrease in the magnetic moment as shown in Fig. 3(f). In addition, there are some contribution of $\mathrm{NiTiO}_{3}$ phases, when the amount of $\mathrm{Ni}$ dopant was over $3 \mathrm{~mol} \%$. Note that the $\mathrm{NiTiO}_{3}$ is antiferromagnetic with Neel temperature $\left(T_{\mathrm{N}} \sim 23 \mathrm{~K}\right)$ in bulk. ${ }^{29)}$ However, it exhibited weeak-ferromagnetism below $250 \mathrm{~K}$ in thin film or room temperature ferromagnetism in nanoparticles. ${ }^{30,31)}$ Thus, we suggest that room temperature ferromagnetism in Ni-doped $\mathrm{Bi}_{0.5} \mathrm{~K}_{0.5} \mathrm{TiO}_{3}$ nanocrystals may be originated from both intrinsic reason caused by the $\mathrm{Ni}$ ion solution in $\mathrm{Bi}_{0.5} \mathrm{~K}_{0.5} \mathrm{TiO}_{3}$ crystal and extrinsic reason caused by segregation of $\mathrm{NiTiO}_{3}$ phase.

Figure 4(a) shows the temperature dependence of magnetization in $\mathrm{Bi}_{0.5} \mathrm{~K}_{0.5} \mathrm{Ti}_{0.99} \mathrm{Ni}_{0.01} \mathrm{O}_{3}$ under an applied field of 

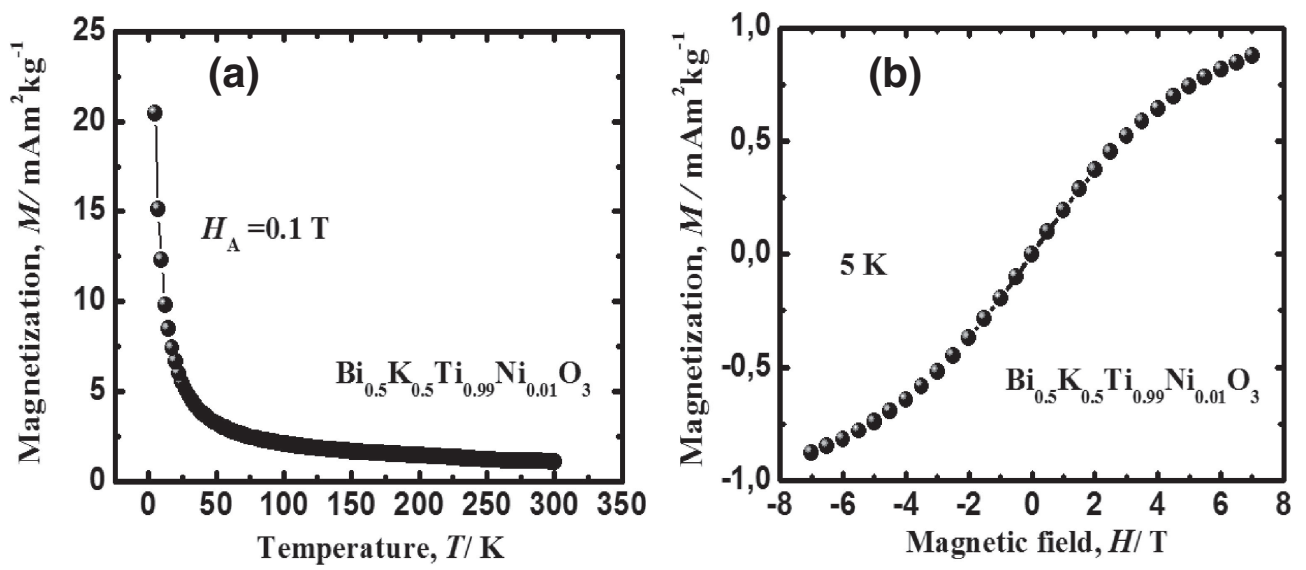

Fig. 4 (a) The $M-T$ curve for the $\mathrm{K}_{0.5} \mathrm{Bi}_{0.5} \mathrm{TiO}_{3}$ samples at $0.1 \mathrm{~T}$ magnetic field with $1 \mathrm{~mol} \%$ Ni doping concentration and (b) $M-H$ curve of the $\mathrm{Bi}_{0.5} \mathrm{~K}_{0.5} \mathrm{TiO}_{3}$ samples with $1 \mathrm{~mol} \% \mathrm{Ni}$ doping concentration at $5 \mathrm{~K}$.

$0.1 \mathrm{~T}$. Figure $4(\mathrm{~b})$ shows the $M-H$ curve of $\mathrm{Bi}_{0.5} \mathrm{~K}_{0.5} \mathrm{Ti}_{0.99}$ $\mathrm{Fe}_{0.01} \mathrm{O}_{3}$ samples up to $7 \mathrm{~T}$ at $5 \mathrm{~K}$. The $\mathrm{Bi}_{0.5} \mathrm{~K}_{0.5} \mathrm{Ti}_{0.99} \mathrm{Ni}_{0.01} \mathrm{O}_{3}$ samples exhibited no saturation even at very high magnetic field. The magnetization was found to be $\sim 0.875 \mathrm{Am}^{2} / \mathrm{kg}$ at applied magnetic field of $7 \mathrm{~T}$. The average magnetic moment per formula unit in Bohr magneton $\left(\mu_{\mathrm{B}}\right)$ was calculated using the following equation $\mu_{B}=\left(M \mathrm{x} M_{\mathrm{S}}\right) / 5585$ where $M$ is the molecular weight of the sample and $M_{\mathrm{S}}$ is the saturation magnetization. ${ }^{32)}$ Here, we note that the magnetic signal of $\mathrm{Bi}_{0.5} \mathrm{~K}_{0.5} \mathrm{Ti}_{0.99} \mathrm{Ni}_{0.01} \mathrm{O}_{3}$ samples was not saturated and it was strong competition between paramagnetism and ferromagnetism. However, we can use this equation to roughly estimate the magnetic moment of samples. The average magnetic moment per $\mathrm{Ni}$ atom is $3.44 \mu_{\mathrm{B}} / \mathrm{Ni}$. When in octahedral coordination, $\mathrm{Ni}^{2+}$ has a spin configuration of $t_{2 \mathrm{~g}}[\uparrow \uparrow \uparrow \downarrow \downarrow \downarrow] e_{\mathrm{g}}[\uparrow \uparrow]\left(M_{\text {spin }}=2 \mu_{\mathrm{B}} / \mathrm{Ni}\right)$. Assuming a low spin state, the spin configurations of $\mathrm{Ni}^{3+}$ and $\mathrm{Ni}^{4+}$ are $t_{2 \mathrm{~g}}[\uparrow \uparrow \uparrow \downarrow \downarrow \downarrow] e_{\mathrm{g}}[\uparrow]\left(M_{\text {spin }}=1 \mu_{\mathrm{B}} / \mathrm{Ni}\right)$ and $t_{2 \mathrm{~g}}[\uparrow \uparrow \uparrow \downarrow \downarrow \downarrow]\left(M_{\text {spin }}=\right.$ $\left.0 \mu_{\mathrm{B}} / \mathrm{Ni}\right)$, respectively. Thus, $\mathrm{Ni}^{2+}$ and $\mathrm{Ni}^{3+}$ are magnetic but $\mathrm{Ni}^{4+}$ is non-magnetic. Therefore, it is worthwhile to make a remark on the value of the measured strength of magnetization in Ni-doped $\mathrm{Bi}_{0.5} \mathrm{~K}_{0.5} \mathrm{TiO}_{3}$ samples in comparison with the expected spin moments of $M_{\text {spin }}=2 \mu_{\mathrm{B}} / \mathrm{Ni}$ for $\mathrm{Ni}^{2+}$ and $1 \mu_{\mathrm{B}} / \mathrm{Ni}$ for $\mathrm{Ni}^{3+}$ ions, which is rather small compared to the experimental value. Ogale et al. and Hong et al. reported that the possibility of an additional orbital contribution to the magnetic moment of an ion through a relaxation of orbital angular momentum quenching. ${ }^{33,34)}$ This assumption seems to be convincing because, when the Ni-added amount is increased, the magnetic moment decreased due to an enhancement of quenching through an increase in dopantdopant associations and/or due to an increases in the antiferromagnetic super-exchange coupling strength between two neighboring magnetic impurity ions via a nearly $\mathrm{O}^{2-}$ ions. ${ }^{35)}$ In addition, it is possible to enhance magnetization due to contribution of magnetism rising from $\mathrm{O}$ - and/or Tivacancies.

\section{Conclusion}

The room-temperature ferromagnetism was obtained from introduction of $\mathrm{Ni}$ ions to lead-free $\mathrm{Bi}_{0.5} \mathrm{~K}_{0.5} \mathrm{TiO}_{3}$ ferroelectric materials. The low solid solution of $\mathrm{Ni}$ in $\mathrm{Bi}_{0.5} \mathrm{~K}_{0.5} \mathrm{TiO}_{3}$ structure resulted in $\mathrm{NiTiO}_{3}$ phase when $\mathrm{Ni}$ concentration was added over $3 \mathrm{~mol} \%$. The room-temperature ferromagnetism in Ni-doped $\mathrm{Bi}_{0.5} \mathrm{~K}_{0.5} \mathrm{TiO}_{3}$ samples could be contributed by intrinsic reason due to presence of $\mathrm{Ni}$ ion in $\mathrm{Bi}_{0.5} \mathrm{~K}_{0.5} \mathrm{TiO}_{3}$ crystal and by extrinsic reason due to segregation of $\mathrm{NiTiO}_{3}$ clusters when $\mathrm{Ni}$ concentration was over $3 \mathrm{~mol} \%$ threshold. The replacement of Ti cations at octahedral site by $\mathrm{Ni}$ cations of $\mathrm{Bi}_{0.5} \mathrm{~K}_{0.5} \mathrm{TiO}_{3}$ nanocrystalline resulted in the reduction of band gap. The pristine $\mathrm{Bi}_{0.5} \mathrm{~K}_{0.5} \mathrm{TiO}_{3}$ had a band gap of $3.31 \mathrm{eV}$ and it decreased to $2.96 \mathrm{eV}$ for $3 \mathrm{~mol} \% \mathrm{Ni}$-dopant. We expect that this way can be further developed new lead-free multiferroics materials.

\section{Acknowledgment}

This research is funded by Vietnam National Foundation for Science and Technology Development Vietnam (NAFOSTED) under grant number 103.02-2012.62. Sunglae Cho acknowledges the support from Energy Efficiency \& Resources program of the Korea Institute of Energy Technology Evaluation and Planning (KETEP) funded by the Korean Ministry of Knowledge Economy (20132020000110).

\section{REFERENCES}

1) D. I. Khomskii: J. Magn. Magn. Mater. 306 (2006) 1-8.

2) A. P. Pyatakov and A. K. Zvezdin: Phys. Usp. 55 (2012) 557-581.

3) N. A. Spaldin and M. Fiebig: Science 309 (2005) 391-392.

4) N. A. Hill: J. Phys. Chem. B 104 (2000) 6694-6709.

5) J. Silva, A. Reyes, H. Esparza, H. Camcho and L. Fuentes: Int. Ferroelectric. 126 (2011) 47-59.

6) G. Zhang, H. Wu, Q. Huang, C. Yang, F. Huang, F. Liao and J. Lin: Sci. Rep. 3 (2013) 1265.

7) Y. Wang, J. Hu, Y. Lin and C. W. Nan: NPG Asia Mater. 2 (2010) 6168.

8) J. P. Velev, S. S. Jaswal and E. Y. Tsymbal: Philos. Trans. R. Soc. A 369 (2011) 3069-3097.

9) X. K. Wei, Y. T. Su, Y. Sui, Q. H. Zhang, Y. Yao, C. Q. Jin and R. C. Yu: J. Appl. Phys. 110 (2011) 114112.

10) Z. Ren, G. Xu, X. Wei, Y. Liu, X. Hou, P. Du, W. Weng, G. Shen and G. Han: Appl. Phys. Lett. 91 (2007) 063106.

11) L. M. Oanh, D. B. Do, N. D. Phu, N. T. P. Mai and N. V. Minh: IEEE Trans. Magn. 50 (2014) 2502004. 
12) C. Liu, C. Jiang, Z. Zhong and Y. Zhou: Mater. Sci. Forum 687 (2011) $174-178$.

13) L. E. Cross: Nature (London) 432 (2004) 24

14) N. D. Quan, L. H. Bac, D. V. Thiet, V. N. Hung and D. D. Dung: Adv. Mater. Sci. Eng. 2014 (2014) 365391.

15) Y. Wang, G. Xu, X. Ji, Z. Ren, W. Weng, P. Du, G. Shen and G. Han: J. Alloy. Compd. 475 (2009) L25-L30.

16) Y. Wang, G. Xu, L. Yang, Z. Ren, X. Wei, W. Weng, P. Du, G. Shen and G. Han: Mater. Sci. Poland 27 (2009) 471-476.

17) D. Yao, X. Zhou and S. Ge: Appl. Surf. Sci. 257 (2011) 9233-9236.

18) R. D. Shannon: Acta Crystallogr. A 32 (1976) 751-767.

19) I. A. Sluchinskaya, A. I. Lebedev and A. Erko: Phys. Solid State 56 (2014) 449-455.

20) S. K. Das, R. N. Mishra and B. K. Roul: Solid State Commun. 191 (2014) 19-24.

21) R. Niishiro, H. Kato and A. Kudo: Phys. Chem. Chem. Phys. 7 (2005) 2241-2245.

22) B. W. Faughnan: Phys. Rev. B 4 (1971) 3623-3636.

23) Y. Hu, W. Dong, F. Zheng, L. Fang and M. Shen: Appl. Phys. Lett. 105 (2014) 082903

24) T. H. Xie, X. Sun and J. Lin: J. Phys. Chem. C 112 (2008) 9753-9759.

25) T. L. Phan, P. Zhang, D. S. Yang, T. D. Thanh, D. A. Tuan and S. C.
Yu: J. Appl. Phys. 113 (2013) 17E305.

26) T. Shimada, Y. Uratani and T. Kitamura: Appl. Phys. Lett. 100 (2012) 162901.

27) I. R. Shein and A. L. Ivanovskii: Phys. Lett. A 371 (2007) 155-159.

28) A. Sundaresan, R. Bhargavi, N. Rangarajan, U. Siddesh and C. N. R. Rao: Phys. Rev. B 74 (2006) 161306.

29) Y. Ishikawa and S. Akimoto: J. Phys. Soc. Japan 13 (1958) 1298-1310.

30) S. Yuvaraj, V. D. Nithya, K. S. Fathima, C. Sanjeeviraja, G. K. Selvan, S. Arumugam and R. K. Selva: Mater. Res. Bull. 48 (2013) 1110-1116.

31) T. Varga, T. C. Droubay, M. E. Bowden, R. J. Colby, S. Manandhar, V. Shutthanandan, D. Hu, B. C. Kabius, E. Apra, W. A. Shelton and S. A. Chambers: J. Vac. Sci. Technol. B 31 (2013) 030603.

32) S. Singhal and K. Chanda: J. Solid State Chem. 180 (2007) 296-300.

33) S. B. Ogale, R. J. Choudhary, J. P. Buban, S. E. Lofland, S. R. Shinde, S. N. Kale, V. N. Kulkarni, J. Higgins, C. Lanci, J. R. Simson, N. D. Browning, S. D. Sarma, H. D. Drew, R. L. Greene and T. Venkatesan: Phys. Rev. Lett. 91 (2003) 077205.

34) N. H. Hong, J. Sakai and A. Hassini: Appl. Phys. Lett. 84 (2004) 26022604.

35) Y. R. Park, S. L. Choi, J. H. Lee and K. J. Kim: J. Korean Phys. Soc. 50 (2007) 638-642. 